See discussions, stats, and author profiles for this publication at: https://www.researchgate.net/publication/346144058

\title{
Multiple criteria assessment of sustainability programs in the textile industry
}

Article in International Transactions in Operational Research · September 2020

DOI: 10.1111/itor.12871

6 authors, including:

Antonio Lombardi

São Paulo State University

2 PUBLICATIONS 1 CITATION

SEE PROFILE

Miguel Angel Ortiz Barrios

Corporación Universidad de la Costa

60 PUBLICATIONS 325 CITATIONS

SEE PROFILE
Valerio Salomon

São Paulo State University

79 PUBLICATIONS 495 CITATIONS

SEE PROFILE

Anna Greda

Centrum PUCP

18 PUBLICATIONS 238 CITATIONS

SEE PROFILE

Some of the authors of this publication are also working on these related projects:

Education, Entrepreneurship and Entrepreneurial Education View project

PRODUCTION View project 


\title{
Multiple criteria assessment of sustainability programs in the textile industry
}

\author{
Antonio Lombardi Netto ${ }^{a}(D)$, Valerio A.P. Salomon ${ }^{a} *(1)$, \\ Miguel A. Ortiz-Barrios b (iD, Anna K. Florek-Paszkowskac ${ }^{\text {iD }}$, Antonella Petrillo ${ }^{d}$ \\ and Otavio J. De Oliveira ${ }^{\mathrm{a}}$ (iD \\ ${ }^{a}$ Department of Production, Universidade Estadual Júlio de Mesquita Filho, Av. Ariberto P. Cunha 333, \\ Guaratinguetá, SP 12516-410, Brazil \\ ${ }^{\mathrm{b}}$ Department of Industrial Management, Agroindustry and Operations, Universidad de la Costa CUC, \\ 58th Street \# 55-66, Barranquilla, Colombia \\ ${ }^{\mathrm{c}}$ Urbanización Los Álamos de Monterrico, Jirón Daniel Alomía Robles 125, Santiago de Surco 15023, Perú \\ ${ }^{\mathrm{d}}$ Engineering Department, University of Naples Parthenope, Napoli, Campania, \\ Via Ammiraglio Ferdinando Acton, 38, Napoli, NA 80133, Italia \\ E-mail: antonio.lombardi@unesp.br[LombardiNetto]; valerio.salomon@unesp.br [Salomon]; mortiz1@cuc.edu.co \\ [Ortiz-Barrios]; aflorekpaszkowska@pucp.edu.pe [Florek-Paszkowska]; antonella.petrillo@uniparthenope.it [Petrillo]; \\ otavio.oliveira@unesp.br [De Oliveira]
}

Received 25 March 2020; received in revised form 29 May 2020; accepted 27 August 2020

\begin{abstract}
To survive in the long term, business needs to profit, controlling environmental impacts with social responsibility. Sustainability programs involve the integration of social and environmental issues in business models and organizational processes. The assessment of sustainability programs is a problem of multiple criteria decision analysis (MCDA). This work presents applications of MCDA for the assessment of sustainability programs in the textile industry. Applied methods for MCDA are analytic hierarchy process (AHP) and the technique for the order of preference by similarity to ideal solution (TOPSIS). The reasons to apply AHP and TOPSIS include providing an assessment index, ranging from 0 to 1 , and that the MCDA model is expected to have more criteria than alternatives. Therefore, an application of other methods, such as data envelopment analysis, could be prejudiced. Concepts from the triple bottom line, economic, social as well as environmental criteria were inserted in the proposed model. Sustainability programs of six leading companies from the Brazilian textile industry were evaluated. The main finding of the research is that AHP and TOPSIS resulted in similar evaluations for sustainability programs. Both methods resulted in the same rank of alternatives. However, with TOPSIS, companies' sustainability indices were more disperse, varying from 0.10 to 0.92 against a range from 0.23 to 0.69 with AHP.
\end{abstract}

Keywords: analytic hierarchy process; multiple criteria decision analysis; sustainability; technique for order of preference by similarity to ideal solution; textile industry

*Corresponding Author.

(C) 2020 The Authors.

International Transactions in Operational Research (C) 2020 International Federation of Operational Research Societies Published by John Wiley \& Sons Ltd, 9600 Garsington Road, Oxford OX4 2DQ, UK and 350 Main St, Malden, MA02148, USA. 


\section{Introduction}

Sustainability is the ability of a business to survive in the long term (Bansal and Des Jardine, 2014). The word was first linked to ecological or environmental issues. Then, "sustainability" has evolved to include economic and social issues (Eccles et al., 2014). Thereby, to survive, in the long term, companies need to do their business profitably, but also controlling the environmental impact with social responsibility. There are usually three recognizable and intertwined sustainability dimensions: economic, environmental, and social (Elkington, 1999). These are the triple bottom-line (TBL) elements. Traditionally, corporate balance sheets have only one bottom line, expressing profits. Taking a sustainable approach, corporations should express, besides profits, also how beneficial their actions were regarding their community (social stakeholders in general, as well as customers and suppliers) and the environment (Fontaine, 2013).

The vast majority of research and practice regarding sustainable supply chains has followed an instrumental logic, which has led firms and supply chain managers to place economic interests ahead of environmental and social interests (Montabon et al., 2016). No continuity on empirical research disables the demonstration of relations as well as influences of TBL elements over one another (Svensson et al., 2018). In practice, development and implementation of sustainability programs consider TBL. Sustainability programs involve the integration of social and environmental issues in business models and organizational processes (Eccles et al., 2014). In the literature, no method is proposed to evaluate sustainability programs among different companies. With the assessment of its sustainability program, a company may evaluate its ability to survive in the long term. Therefore, there is a gap between the existing theory and practical needs. A research question arises: Is it possible to assess sustainability programs of different companies?

This work proposes a model of multiple criteria decision analysis (MCDA) for the assessment of sustainability programs. The model is applied with data from real-world companies: the leaders of the Brazilian textile industry. Since the objective of its analysis is the comparison of sustainability programs, TBL was incorporated in the MCDA model. Aiming at a reliable comparison, companies for only one industrial branch were considered as alternatives. This is an important industry with processes from complex supply chains, beginning with agricultural raw material suppliers. In 2018, more than 8 billion goods were produced, in a US\$50 billion market (ABIT, 2019).

The novelty of this work comes with the proposal of an MCDA model and its application to real-world data. MCDA has been developed to support decision makers in their decision processes (Ishizaka and Nemery, 2013). There are several methods for MCDA, usually referred to by acronyms. An alphabetical list of frequently applied methods, with seminal references, is as follows:

- AHP, analytic hierarchy process (Saaty, 1974);

- ANP, analytic network process (Saaty, 1996);

- DEA, data envelopment analysis (Charnes et al., 1978);

- ELECTRE, elimination and choice translating reality (Roy, 1968);

- MACBETH, measuring attractiveness by category-based evaluation technique (Bana e Costa and Vansnick, 1994);

- MAUT/MAVT, multiattribute utility/value theory (Keeney and Raiffa, 1976);

- PROMETHEE, preference ranking organization method for enriched evaluation (Brans and Vincke, 1985); 
- TOPSIS, technique for order of preference by similarity to ideal solution (Hwang and Yoon, 1981).

AHP and DEA are two leading MCDA methods by the number of applications and publications (Khan et al., 2015). Then, AHP and DEA were first considered to be applied to this work, since application of both methods provides an assessment index, ranging from 0 to 1 . Notwithstanding, there were expected more criteria than alternatives, prejudicing DEA application.

AHP leadership in the MCDA literature became evident from the early 1990s (Wallenius et al., 2008). Nevertheless, together with AHP development in practice and theory, some criticisms appeared. One type of criticism focused on results, with some cases of AHP applications giving incorrect results (Barzilai, 1998). This criticism was refuted by the argumentation that wrong models may give wrong results. Then, other MCDA models were developed with AHP for these cases, giving right results (Whitaker, 2007a). The question became a matter of knowledge on method application, and not a matter of method flaw.

The second type of AHP criticism, focusing on the process, was first driven by MAUT users (Dyer, 1990), against the "arbitrariness" of pairwise comparisons. However, only MAUT needs to be dictated by axioms and concepts of utility theory, but not MAVT (McCord and De Neufville, 1983). In fact, this criticism was responsible for developments in AHP theory, for instance, with nonlinear scales of comparisons (Lootsma, 1993), or algorithms to reduce the number of comparisons (Harker, 1987).

Rank reversal (RR) is another interesting criticism, which was first associated with AHP (Belton and Gear, 1983). Nowadays, it is clear that other methods for MCDA, such as ELECTRE, MAUT, PROMETHEE, and TOPSIS, may also lead to RR (Triantaphyllou, 2000). An RR situation occurs, for instance, when an old alternative is deleted or when a new alternative is inserted and the rank of alternatives changes. There are some legitimate cases of RR, as in resource allocation, but there are illegitimate cases too, as in supplier selection (Salomon et al., 2016). Therefore, the first discussion will be on RR legitimacy of the problem. For the assessment of sustainability programs, it seems unfair, for instance, that one of the best alternatives becomes one of the worst in a rank of less than a dozen alternatives, if a new alternative is added or an old alternative is deleted. Then, for the problem addressed in this work, $\mathrm{RR}$ is not legitimate.

Combining absolute measurement with ideal synthesis, one can avoid RR in AHP (Saaty et al., 2009), as presented in Section 3. Thus, applying AHP will solve the problem, assessing sustainability programs. Nevertheless, according to the MCDA literature, single-method applications are subject to flawless process (Ishizaka and Lusti, 2004) or inaccurate results (Sato, 2004). This work presents the full application of two MCDA methods. If results from both methods are similar, their validity may be presumed (Whitaker, 2007b; Yatsalo et al., 2007; Linkov and Moberg, 2012).

The need for MCDA application for sustainability assessment, framing it with TBL, is emerging (Subramanian et al., 2014; Stoycheva et al., 2018; Rycroft et al., 2019). In accordance, there are studies with a single-method application (Medel-González. et al., 2016) or a hybrid-method application (Metaxas et al., 2013). Therefore, with two-method nonhybrid applications, this paper presents a trendless research. This is a methodological contribution of this paper to the literature on MCDA and sustainability. Finally, this work presents TBL-based attributes instead of literature collection of attributes from selected papers. 
Following this Introduction, Section 2 backgrounds the proposed index with TBL concepts. Section 3 summarizes MCDA concepts needed for AHP and TOPSIS applications. Section 4 presents AHP and TOPSIS applications to evaluate sustainability programs of six leading companies in the Brazilian textile industry. Section 5 concludes the paper with conclusions and suggestions for further research.

\section{Background}

\subsection{Sustainability, multiple criteria decision analysis, and textile industry}

Formerly called the World Commission on Environment and Development (WCED), the Brundtland Commission aims to help nations of the world toward the goal of sustainable development (Kono, 2014). Sustainable development is development that meets the needs of the present generation without compromising the ability of future generations to meet their own needs (Borowy, 2014). This seminal concept on sustainability was introduced in our common future report (WCED, 1987).

Business sustainability is a TBL-based concept, thereby including economic, social, and environmental efforts (Svensson and Wagner, 2015). For business supporting all the three TBL pillars, tools and methods are needed to link their decisions to sustainability impacts (Hutchins et al., 2019). "Circular economy" is a close concept of business sustainability: a regenerative system in which resource input and waste, emissions, and energy leakage are minimized by slowing, closing, and narrowing material and energy loops. This can be achieved through long-lasting design, maintenance, recycling, refurbishing, remanufacturing, repair, and reuse (Geissdoerfer et al., 2018). Sustainability in the development and manufacture of new products is a widely accepted strategy (Kaebernick et al., 2003).

MCDA is a discipline of methods and tools for decision analysis, considering more than two, and sometimes conflicting, objectives (Zionts, 1979; Koksalan et al., 2011). MCDA is divided into two branches (Hwang and Yoon, 1981; Zavadskas et al., 2014): multiattribute decision analysis (MADA) and multiobjective decision analysis (MODA). MADA deals with a short set of alternatives, sometimes referred to as discrete decision problems. In the extreme, MADA may solve a problem with only two alternatives. MODA deals with a larger set of alternatives, also referred to as continuous decision problems. At the other extreme, MODA may deal with infinite alternatives. This paper is about MADA. However, we will refer to it as MCDA, as it is a more common term.

The Brazilian textile industry is the research object of this paper. This choice is justified by the importance of this industry. By the end of 2018, Brazil was the fifth largest country by area, the sixth by population, and the eighth by gross domestic product (International Monetary Fund, 2020). According to these indicators, Brazil is the top country in Latin America, South America, Portuguese-speaking countries, and in the Southern Hemisphere (only 7\% of Brazil's area is in the Northern Hemisphere). The Brazil textile industry is one of the world's top 10 industries for many products. For instance, Brazil is the second largest major supplier of indigo and the third largest fabric producer (Do Amaral et al., 2018; Appel, 2019) Therefore, Brazil is a representative country for a case study on sustainability. 
Table 1

Documents published on MCDA, sustainability, and textile industry

\begin{tabular}{lr}
\hline Search & Result \\
\hline MCDA & 40,630 \\
Sustainability & 209,203 \\
Textile industry & 168,818 \\
MCDA and sustainability & 2766 \\
MCDA and textile industry & 139 \\
Sustainability and textile industry & 1342 \\
MCDA and sustainability and textile industry & 15 \\
\hline
\end{tabular}

Source: https://www.scopus.com.

There are few studies on textile industry addressing TBL (Rodrigues et al., 2020). Due to Brazil's large size and pollution potential, the assessment of Brazilian textile industry is necessary to minimize negative impacts (Appel, 2019). Homogeneous alternatives are expected with the limitation to just one industrial branch. Thereby, it is intended to avoid comparisons of "apples to oranges." Brazilian supply chains to the textile industry encompass all economic sectors: raw material from agribusiness, manufactured clothes, and finished goods stored, sold and delivered by service providers. They are typically nonvertical supply chains (Cruz-Moreira, 2002), with stages performed independently by primary production, manufacturing companies, and service providers.

\subsection{Bibliometrics}

Since sustainability is a multidimensional subject, a bibliography search was performed on sustainability and MCDA. One of the present issues regarding sustainability reporting tools is the lack of standardization in terms of criteria and proposed methods (Siew, 2015). This issue scatters the establishment of reference points for corporate sustainable performance. Therefore, MCDA methods may be applied to evaluate sustainability of manufacturing industries.

Previously, AHP and TOPSIS were proposed to benchmark sustainability programs (Metaxas et al., 2013). However, this comparison was not based on real-world companies, but "estimates in a logical context." ANP was also applied for the evaluation of corporate sustainability, resulting in a sustainability index (Medel-González et al., 2015). Four power plants in Cuba were evaluated by this index, which was based on balanced scorecard (BSC) theory (Kaplan and Norton, 1992). Primary criticism on BSC may be summarized as the flawless process to provide a score (Jensen, 2001) and driving no environmental and no social measures, focusing on economic measures (Kennerley and Neely, 2002). Hybrid-method applications in the textile industry include maintenance management (Shyjith et al., 2008; Ilangkumaran and Kumanan, 2009), supply chain management (Nazam et al., 2015), and sustainability assessment (Acar et al., 2015). Another hybrid-method application studied a single Turkish company, using a local database instead of the Global Report Initiative (GRI). Their MCDA model is not TBL based, with four criteria different from economic, environmental, and social.

Table 1 presents the results from the article title, abstract, and keyword search in Scopus (https://www.scopus.com.). The terms "MCDA," "MCDM," "multiple criteria," and "multicriteria" were searched for MCDA; for textile industry, just "textile" was searched. 
Only 15 documents were published involving three keywords simultaneously. This scarcity of works is evidence of the originality of this paper. In other words, documents on MCDA, sustainability, and textile industry represent less than $0.01 \%$ of the total documents on sustainability. Therefore, this paper is a significant contribution to the joint literature on MCDA, sustainability, and textile industry.

A simple indication of the bibliometrics is that the fields of MCDA, sustainability, and textile industry are fertile. However, MCDA could be applied more to solve sustainability problems in the textile industry. This identifies a literature gap on the assessment of sustainability programs in the textile industry's real-world companies. This is the main objective of this work. A multiple criteria assessment model of sustainability programs is presented in Section 4.

\section{Methodology}

\subsection{Research method}

This paper reports a mixed qualitative-quantitative research (Creswell, 2013), combining case study (Yin, 2017) and mathematical modeling (Bertrand and Fransoo, 2002). The Brazilian textile industry is the research object. This object is previously introduced in Sections 1 and 2, along with the justification for its choice. Details of the object are presented in Section 4, as alternatives in an MCDA model, which are sustainability programs from the Brazilian textile industry.

Mathematical modeling of MCDA runs through three main steps, summarized as follows (Salgado et al., 2012): structuring (identification of decision objective, criteria, and alternatives), measurement (designation of weights for the criteria and scores for the alternatives), and synthesis of the results.

There are several methods for MCDA (Ishizaka and Nemery, 2013; Zavadskas et al., 2014). Important differences among the methods are the ways to proceed through the steps. A singlemethod application can solve a problem. However, it may be subjected to incorrect proceedings or invalid results (Belton and Gear, 1983). To avoid those issues, variations of the original method for MCDA were developed, for instance, fuzzy TOPSIS (Shiu et al., 2019). In fuzzy TOPSIS, components of the decision matrix are fuzzy numbers, instead of crisp numbers in the original TOPSIS. With fuzzy numbers, uncertainty is incorporated in problem-solving. Another approach is hybrid-method application. One step, or some parts, is performed according to one method, and other steps, or parts, are performed according to other methods. For instance, with a hybrid AHP-PROMETHEE application, strengths of both methods were obtained in an application to the automobile industry (Oliveira et al., 2018).

This research planned nonhybrid applications of two original methods for MCDA. It first intends to solve a real-world problem, within a case study. Another point is to present contributions out of hybridism trend. Thereby, this paper aims to present that the application for pure MCDA methods is still scientifically worthy.

Figure 1 presents the research flow comprising five phases: problem definition, methods selection, Method 1 application, Method 2 application, and results comparison. Applications of Methods 1 and 2 may be independent; in this research they were partially sequential. Some data collected and 


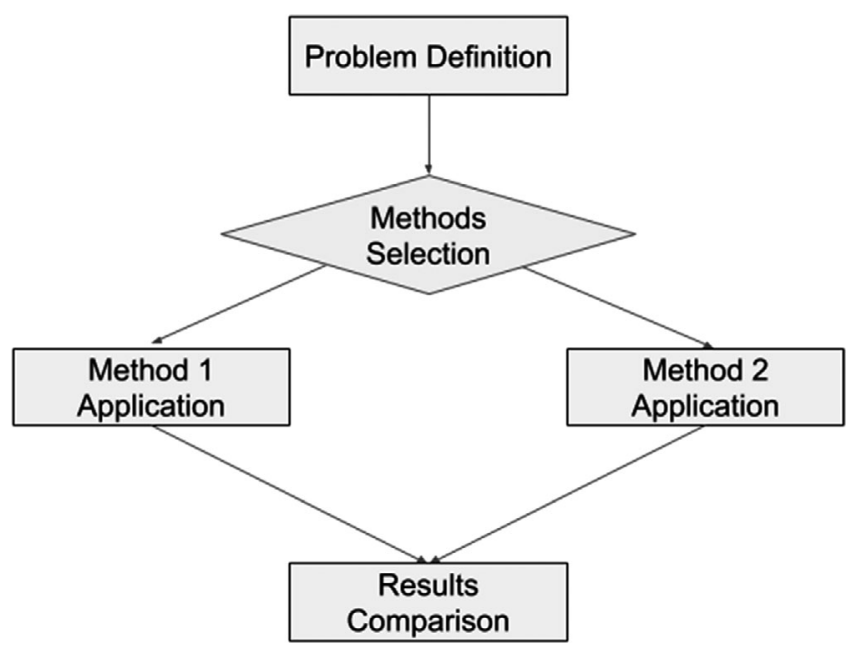

Fig. 1. Research flow.

results processed with Method 1 application were appropriate for Method 2 application. This is a type of hybridism. However, a decision maker has an option of not using these values.

In the first phase, it is very important to define the decision objective, for instance "selection of one alternative" or "ranking all alternatives." During the problem definition, characteristics, and not names, of expected alternatives and criteria must be described. Lastly, expected characteristics for results are required: for instance, "alternatives ranked" or "alternatives gathered in classes." Roughly describing objectives, criteria, alternatives, and results are required for the methods selection. With those items defined, for instance, if there is dependency among alternatives or among criteria, ANP (Saaty, 2005) would be a proper method for MCDA.

The selection of a method is a decision itself (Watróbski et al., 2019). "The analyst can then adopt an appropriate method to process, the information. This need may not always be the multi-attribute utility approach, or the Saaty approach, or any other specific approach, but that with which the decision-maker feels at ease" (Belton and Gear, 1983). As previously introduced, AHP and TOPSIS were selected for this research. Reasons came from the results of the problem definition, as follows. In this research, the decision objective is the assessment of sustainability programs. In the case of the Brazilian textile industry, there are few companies with sustainability programs reported in the GRI. As commented in Section 4, GRI is a widely consulted database of sustainability programs. Precisely, there are six Brazilian companies reported in GRI as "textile industry" (GRI, 2019). And those companies act independently. Lastly, an index is expected, for instance, ranging from one to zero to assess sustainability programs.

Therefore, AHP and TOPSIS seem to be appropriate methods for MCDA. DEA, another leading MCDA, seems not to fit to the problem. Besides providing a score ranging from 0 to 1, DEA needs that the set of alternatives be greater than the set of criteria, to properly discriminate the alternatives (Li and Reeves, 1999; Bal et al., 2010; Oliveira et al., 2016). Familiarity with an MCDA method is another important reason, as pointed by Belton and Gear (1983). Most coauthors of this paper have applied AHP and TOPSIS previously. Section 3.2 presents how steps of structuring, measurement, and synthesis may be performed with AHP application. Section 3.3 presents how to apply TOPSIS. 


\subsection{Analytic hierarchy process}

AHP is a leading method for MCDA (Khan et al., 2015; Tramarico et al., 2015) developed from the 1970s (Saaty, 1974; Saaty and Rogers, 1976; Saaty, 1977). Originally, the AHP application ran with relative measurement and normal synthesis. From the 1980s, advances in theory proposed different ways to apply AHP including absolute measurement, also called "ratings" (Saaty, 1986), and ideal synthesis (Millet and Saaty, 2000). The original relative measurement and normal synthesis are more frequent ways to apply AHP (Salomon, 2016). In this research, AHP was applied with absolute measurement and normal synthesis, as explained. One main reason is that alternatives are independent of each other, as mentioned in Section 2.

In relative measurement, alternatives and criteria are compared pairwise. Pairwise comparisons in AHP are generally based on the Saaty scale also known as the fundamental scale of absolute numbers (Saaty, 1977, 2010). The Saaty scale is a linear 1-9 scale, where "1" means equal importance between the two compared objects; " 3 " means that one object is moderately more important than the other; " 5 " means that one object is more important; "7" means that one object is strongly more important; "9" means that one object is extremely more important. The weights of the criteria came from the right eigenvalue $w$ of the pairwise comparison matrix $A$, as in $A w=\lambda_{\max } w$, where $\lambda_{\text {max }}$ is its maximum eigenvalue.

Consistency analysis is an advantage of relative measurement in AHP (Wu et al., 2018). With the Saaty scale, $A$ will be a reciprocal positive matrix: $a_{i j}=1 / a_{j i}$ and $a_{i j} \geq 1$, for all $i=1,2,3, \ldots, n$ and $j=1,2,3, \ldots, n$, where $n$ is the number of objects compared. Therefore, if all $a_{i j}=w_{i} / w_{j}$, then $\lambda_{\max }=n$. Or else, the difference $\lambda_{\max }-n$ is twice the variance of deviations $a_{i j}-w_{i} / w_{j}$, for all $i$ and $j$ (Saaty, 1977). Therefore, the consistency index, $C I=\left(\lambda_{\max }-n\right) /(n-1)$, is a measure of $A$ 's inconsistency.

The consistency ratio, $C R=C I / R I$, is a better measure of $A$ 's inconsistency. $C R$ compares $C I$ to a random index, $R I$, which increases with $n$ (Saaty, 2010). Generally, if $C R>0.1$ then $A$ 's inconsistency is high, comparisons must be revised (Ishizaka and Lusti, 2004). Or else, when $C R \leq 0.1, A$ may be accepted. Therefore, weights for the criteria $\hat{w}$, also called "priorities" (Saaty, 1977), are set normalizing $w$ as in $\hat{w}_{j}=w_{j} / \sum_{j=1}^{n} w_{j}$, where $n$ is the number of criteria.

Normalized weights for the criteria will sum to $100 \%$. After the pairwise comparisons of criteria are completed, alternatives must be pairwise compared according to every criterion, comprising $j$ comparison matrices $A^{j}$. Every comparison matrix needs to pass the consistency checking. Thereby, all $C R^{j}$ must be lower than or equal to 0.1 . Therefore, eigenvectors $w^{j}$ need to be normalized, but replacing $n$ by $m$, the number of alternatives. Those normalized eigenvectors will constitute columns of decision matrix $D$, as in $d_{i j}=w_{i}^{j} / \sum_{i=1}^{m} w_{i}^{j}$, for every $j=1,2,3, \ldots, n$. As mentioned in Section 2, the components of decision matrix $d_{i j}$ are scores for alternatives $i$, according to criteria $j$, also called "local priorities" in AHP.

With absolute measurement, alternatives are compared to standard levels, instead of pairwise comparison. Therefore, since there is no comparison matrix among alternatives, the set of alternatives is not limited to nine, or "seven, plus or minus two" (Saaty and Ozdemir, 2003). Another advantage of absolute measurement is the opportunity to avoid biases. With alternatives being compared to each other, $2 \times 2$ (relative measurement), some historical trends could be kept in mind. Comparing alternatives to standards (absolute measurement) seems to provide unbiased measures (Salomon et al., 2016). 
Table 2

Levels and scores for alternatives absolute measurement

\begin{tabular}{ll}
\hline Level & Score \\
\hline Weak (W) & 0.2 \\
Reasonable (R) & 0.4 \\
Good (G) & 0.6 \\
Very good (V) & 0.8 \\
Excellent (E) & 1.0 \\
\hline
\end{tabular}

In absolute measurement, alternatives are rated one at a time (De Felice and Petrillo, 2013). However, levels of importance and their scores need to be defined before rating alternatives. Table 2 presents levels and scores for alternatives according to a single criterion.

Scores may vary with criteria (De Felice and Petrillo, 2013). In this paper, the same levels and scores will be adopted for every criterion. Even with the scores for alternatives obtained with absolute measurement, criteria must be pairwise compared.

In normal synthesis, scores of alternatives and weights of criteria sum to $100 \%$. Therefore, the decision matrix is a stochastic matrix, with every column summing to 1 (Cagniuc, 2017). Normal synthesis requires stochasticity of decision matrix. Then, with absolute measurement, scores for alternatives may need to be normalized. This is because in absolute measurement, $w_{i}^{j}$ are not from eigenvectors but are from associated values to tables similar to Table 4 (De Felice and Petrillo, 2013).

A decision vector $x$ can be obtained weighting decision matrix $D$ by normalized weights of criteria $\hat{w}$, that is, $x=D \hat{w}$. Decision vector is composed of aggregate scores for alternatives, according to all criteria. The aggregate scores are also called "overall priorities" (Saaty, 1977). Decision vector is a "normal vector," in other words, the sum of its components is equal to 1.

This is one of the main reasons to adopt these AHP applications in this work. Another reason is the proposal of an index ranging from 0 to 1 , that is, an idealized index. Ideal synthesis does not require stochasticity of decision matrix. However, scores for alternatives may need to be normalized, as in $d_{i j}=w_{i}^{j} / \max \left(w_{i}^{j}\right)$. The decision vector $x$ is also obtained weighting $D$ by $\hat{w}$, as in normal synthesis. Decision vector from ideal synthesis is not normal: The sum of its components will be greater than 1 .

\subsection{Technique for order of preference by similarity to ideal solution}

TOPSIS is another leading MCDA method (Khan et al., 2015). AHP and TOPSIS share common ways in their application steps. Often, TOPSIS is applied with three-level hierarchies, absolute measurement, and ideal synthesis. One major difference between AHP and TOPSIS is that pairwise comparisons are not required for the last level.

Data collection in TOPSIS may proceed in the simplest way, with direct attribution of weights $w_{j}$ for criteria $j=1,2,3, \ldots, n$ and scores $w_{i}^{j}$ for the alternatives $i=1,2,3, \ldots, m$ according to criteria $j$. Against this simplicity, hybridism as AHP-TOPSIS (Lin et al., 2008; Joshi et al., 2011; Tyagi et al., 2014) or fuzzy-TOPSIS (Nadaban et al., 2016), or even AHP-fuzzy-TOPSIS 


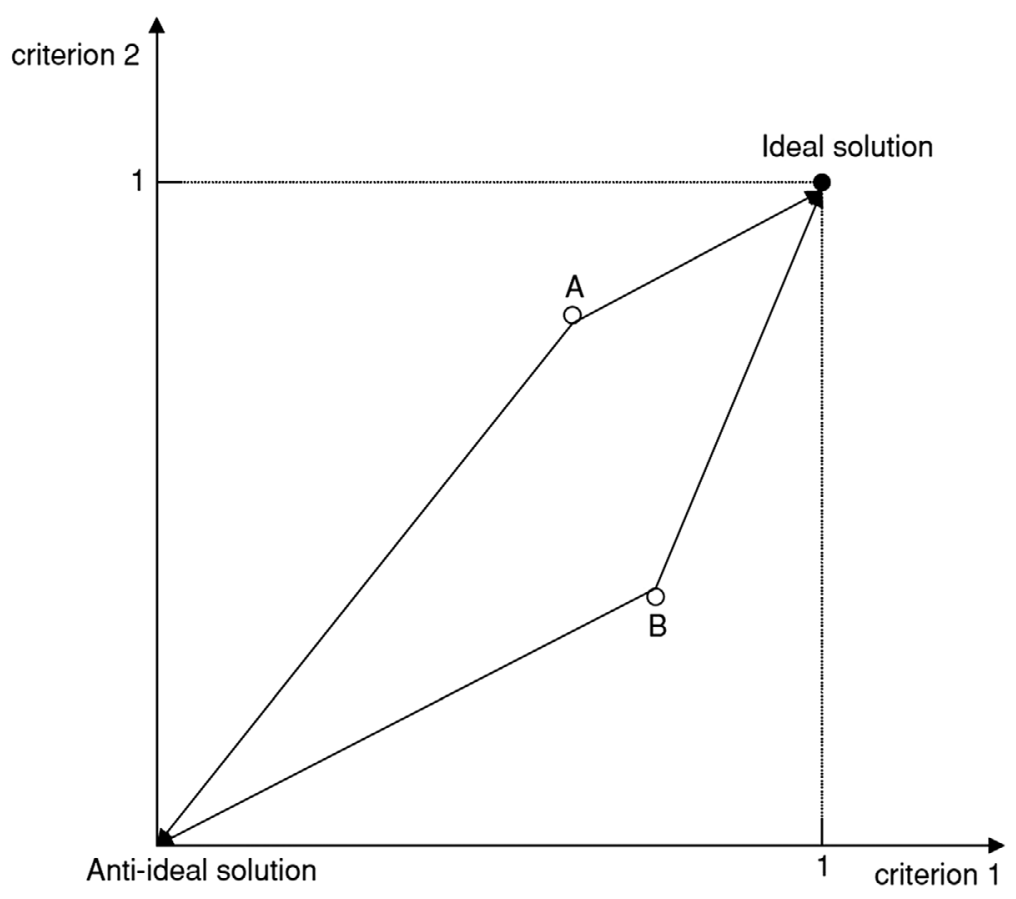

Fig. 2. Two-alternative and two-criterion TOPSIS illustration (Ishizaka and Nemery, 2013).

(Ortiz-Barrios et al., 2020) have been proposed. In this work, original nonhybrid TOPSIS is applied.

TOPSIS is also similar to DEA, since they are methods for MCDA with "goal, aspiration or reference level approach" (Ishizaka and Nemery, 2013). The reference levels are called positiveideal solution (PIS) and negative-ideal solution (NIS) in TOPSIS (Hwang and Yoon, 1981). The best alternative will be the one with the shortest distance from the PIS and the longest distance from the NIS. For instance, in Fig. 2, alternative A is closer to the "ideal solution" PIS than B is and farther from the "anti-ideal solution" NIS (Ishizaka and Nemery, 2013). If the criteria weights are equal, TOPSIS results in a higher overall score for alternative A than B. When the problem has more than two criteria, this picture becomes a spiderweb chart (Ortiz-Barrios et al., 2018).

Ideal synthesis is called "linear normalization" in TOPSIS (Hwang and Yoon, 1981), and normal synthesis is "vector normalization" (Lai et al., 1994). In this work, AHP and TOPSIS are applied with ideal synthesis to result in an index ranging from 0 to 1 .

Both $w$ and $D$ need to be normalized: $\hat{w}_{j}=w_{j} / \sum w_{j}$, as in AHP; $d_{i j}=w_{i}^{j} / \max w_{i}^{j}$, as in AHP; and $\hat{d}_{i j}=d_{i j} \hat{w}_{j}$. As $\hat{w}$, NIS and PIS are row matrices, obtained, respectively, with $A^{-}$and $A^{+}$as $a_{j}^{-}=\min \hat{d}_{i j}$ and $a_{j}^{+}=\max \hat{d}_{i j}$, for $i=1,2,3, \ldots, m$.

Overall scores of alternatives $x_{i}$, also called closeness index in TOPSIS are not obtained weighting $D$ by $\hat{w}$. Instead, $x$ is obtained with a ratio between distances to NIS and PIS: $x_{i}=d_{i}^{-} /\left(d_{i}^{+}+d_{i}^{-}\right)$. In this work, we adopt the Euclidean distances $d^{-}=\sqrt{\sum\left(a_{j}^{-}-\hat{d}_{i j}\right)^{2}}$ and $d^{+}=\sqrt{\sum\left(a_{j}^{+}-\hat{d}_{i j}\right)^{2}}$, due to the more common use than the Manhattan distance (Ishizaka and Nemery, 2013). 


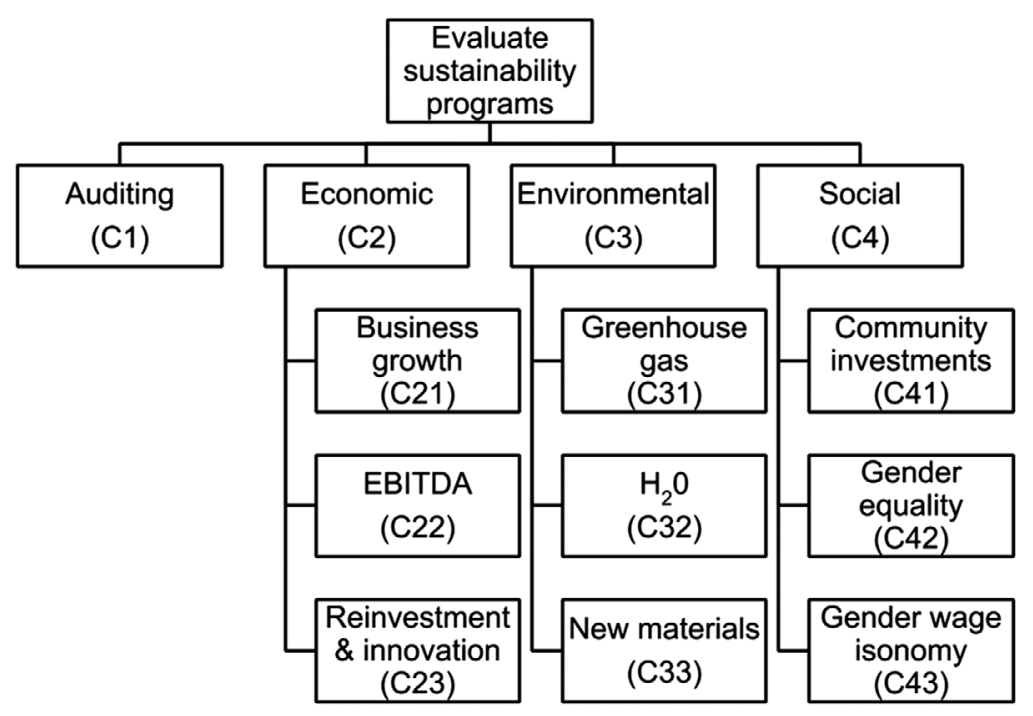

Fig. 3. Three-level hierarchical structure of criteria to assess sustainability programs.

If $x_{i}$ is greater than 0.5 , then alternative $i$ is closer to PIS than NIS, meaning "heaven" to Christians or "profit" for investors (Lai et al., 1994). Otherwise, if alternative $i$ is closer to NIS, meaning "hell" for Christians and "risk" for investors, then $x_{i}$ will be less than 0.5 .

Sensitivity analysis may be performed to evaluate the impact of values directly attributed to $w$ in TOPSIS (Yeh, 2002). Usually, sensitivity analysis is done in a 2D chart, with $w$ on the horizontal axis and $x$ on the vertical axis. As presented in Section 4, $x$ does not linearly vary with $w$ in TOPSIS as in AHP.

\section{AHP and TOPSIS applications}

\subsection{MCDA model}

Figure 3 presents a hierarchy of alphabetically sorted criteria to assess sustainability programs.

Auditing is a subcriteria-less criterion $(\mathrm{C} 1)$. Subcriteria contribute only to a single criterion. For instance, subcriteria $\mathrm{C} 21-\mathrm{C} 23$ only contribute to $\mathrm{C} 2$ and they do not contribute to $\mathrm{C} 3$ and $\mathrm{C} 4$. As can be seen, the proposed hierarchy of attributes is based on TBL concepts, with economic, environmental, and social attributes as major criteria.

Subcriteria C21-C43 are a part of the GRI database, available for public access (GRI, 2019). Looking for a balance among criteria $\mathrm{C} 2-\mathrm{C} 4$, three subcriteria were identified under each criterion. The GRI database has over 54,000 reports, from almost 15,000 companies located in more than 90 countries. ISO 14000 -based GRI is the most widely used standard for sustainability reporting (Marimon et al., 2012).

In this work, the alternatives of the MCDA model are sustainability programs. In the GRI database, sustainability programs are identified by companies' names. For ethical reasons, 
Table 3

Sustainability programs assessed by MCDA

\begin{tabular}{llllll}
\hline Company & Foundation & Employees & Women employed & Gross income [BRL] & Net income [BRL] \\
\hline E1 & 1880 & 8441 & $72 \%$ & 1.95 billion & 318.9 million \\
E2 & 1930 & 2561 & $74 \%$ & Not available & Not available \\
E3 & 1968 & 10,204 & $77 \%$ & Not available & Not available \\
E4 & 1882 & Not available & Not available & Not available & Not available \\
E5 & 1912 & 16,993 & $70 \%$ & 4.6 billion & 471 million \\
E6 & 1964 & 2772 & $66 \%$ & Not available & 483 million \\
\hline
\end{tabular}

Source: GRI (2019).

Table 4

Ratings of sustainability programs

\begin{tabular}{lllllllllll}
\hline Sustainability program & C1 & C21 & C22 & C23 & C31 & C32 & C33 & C41 & C42 & C43 \\
\hline E1 & N & R & R & W & R & G & W & G & G & W \\
E2 & Y & R & G & G & G & R & G & V & G & V \\
E3 & Y & R & W & W & R & W & R & W & G & W \\
E4 & N & R & W & W & W & R & W & G & W & W \\
E5 & Y & V & G & G & W & W & R & R & G & R \\
E6 & N & R & W & W & W & R & W & G & R & W \\
\hline
\end{tabular}

alternatives are not identified by their names, but rather by acronyms E1-E6, with E standing for enterprises. Their names are available in the GRI database, however, this work does not intend the promotion of particular companies. For this work, the data presented in Table 3 are more important than companies' names.

\subsection{AHP application}

Table 4 presents the association of levels proposed in Table 2 to sustainability programs according to every criterion of Fig. 3. This association is based on the GRI database. As mentioned in Section $4.1, \mathrm{C} 1$ is the only subcriteria-less criterion, then it was directly assessed. This was a binary assessment, thereby a sustainability program either has (associated to $\mathrm{Y}$ for yes) or does not have (associated to $\mathrm{N}$ for no) auditing processes. Then, $\mathrm{C} 1$ is the only criterion not assessed with the levels of Table 2.

As can be seen in Table 4, assessment varies with criteria. For instance, E1's sustainability program is good on community investments (C41), gender equality (C42), and $\mathrm{H}_{2} \mathrm{O}(\mathrm{C} 32)$. However, E1's sustainability program has no auditing $(\mathrm{C} 1)$, and it is weak on gender wage isonomy $(\mathrm{C} 43)$, new materials (C33), and reinvestment and innovation (C23). Therefore, there are several opportunities to improve this sustainability program.

Table 5 presents a decision matrix with the association to scores from Table 2. Table 6 presents a decision vector: overall scores obtained from arithmetic mean of scores from Table 5.

Equally weighting criteria result in E2's and E5's sustainability programs with the highest overall scores. These are the only two sustainability programs with overall scores greater than 0.5. 
Table 5

Scores of sustainability programs

\begin{tabular}{|c|c|c|c|c|c|c|c|c|c|c|}
\hline Sustainability program & $\mathrm{C} 1$ & $\mathrm{C} 21$ & $\mathrm{C} 22$ & $\mathrm{C} 23$ & C31 & $\mathrm{C} 32$ & $\mathrm{C} 33$ & $\mathrm{C} 41$ & $\mathrm{C} 42$ & $\mathrm{C} 43$ \\
\hline E1 & 0 & 0.4 & 0.4 & 0.2 & 0.4 & 0.6 & 0.2 & 0.6 & 0.6 & 0.2 \\
\hline E2 & 1 & 0.4 & 0.6 & 0.6 & 0.6 & 0.4 & 0.6 & 0.8 & 0.6 & 0.8 \\
\hline E3 & 1 & 0.4 & 0.2 & 0.2 & 0.4 & 0.2 & 0.4 & 0.2 & 0.6 & 0.2 \\
\hline E4 & 0 & 0.4 & 0.2 & 0.2 & 0.2 & 0.4 & 0.2 & 0.6 & 0.2 & 0.2 \\
\hline E5 & 1 & 0.8 & 0.6 & 0.6 & 0.2 & 0.2 & 0.4 & 0.4 & 0.6 & 0.4 \\
\hline E6 & 0 & 0.4 & 0.2 & 0.2 & 0.2 & 0.4 & 0.2 & 0.6 & 0.4 & 0.2 \\
\hline
\end{tabular}

Table 6

Assessment of sustainability programs (AHP — equally weighted criteria)

\begin{tabular}{lll}
\hline Sustainability program & Overall score & Rank \\
\hline E1 & 0.36 & 4 \\
E2 & 0.64 & 1 \\
E3 & 0.38 & 3 \\
E4 & 0.26 & 6 \\
E5 & 0.52 & 2 \\
E6 & 0.28 & 5 \\
\hline
\end{tabular}

Table 7

Pairwise comparisons and weights for criteria

\begin{tabular}{llllll}
\hline Criterion & $\mathrm{C} 1$ & $\mathrm{C} 2$ & $\mathrm{C} 3$ & $\mathrm{C} 4$ & Weight (\%) \\
\hline Auditing (C1) & 1 & $1 / 1.2$ & $1 / 1.2$ & $1 / 1.2$ & 22 \\
Economic (C2) & 1.2 & 1 & 1 & 1 & 26 \\
Environmental (C3) & 1.2 & 1 & 1 & 1 & 26 \\
Social (C4) & 1.2 & 1 & 1 & 1 & 26 \\
\hline
\end{tabular}

Table 8

Pairwise comparison and weights for economic subcriteria

\begin{tabular}{lllllr}
\hline Subcriterion & C21 & C22 & C23 & Local (\%) & Overall (\%) \\
\hline Business growth (C21) & 1 & 1 & $1 / 1.5$ & 29 & 7 \\
EBITDA (C22) & 1 & 1 & $1 / 1.5$ & 29 & 7 \\
Reinvestment and innovation (C23) & 1.5 & 1.5 & 1 & 42 & 12 \\
\hline
\end{tabular}

Therefore, E1's, E3's, E4's, and E6's sustainability programs need to improve, as their overall scores are below 0.5 , far from ideal.

Tables $7-10$ present pairwise comparisons among criteria and among subcriteria. Comparisons came from consensual judgments, provided by two coauthors of this paper who are expert consultants on MCDA and sustainability for Brazilian industries. For the matrix in Table $7, \lambda_{\max }=4$ and for the matrices in Tables $8-10, \lambda_{\max }=3$. For all those matrices, $C R=0$. Thereby, all comparison matrices are fully consistent. Local weights were obtained with normalization of comparison 
Table 9

Pairwise comparison and priorities for environmental subcriteria

\begin{tabular}{lllllr}
\hline Subcriterion & C31 & C32 & C33 & Local (\%) & Overall (\%) \\
\hline Greenhouse gas (C31) & 1 & 1 & $1 / 1.2$ & 31 & 8 \\
$\mathrm{H}_{2} \mathrm{O}(\mathrm{C} 32)$ & 1 & 1 & $1 / 1.2$ & 31 & 8 \\
New materials (C33) & 1.2 & 1.2 & 1 & 38 & 10 \\
\hline
\end{tabular}

Table 10

Pairwise comparison and priorities for social subcriteria

\begin{tabular}{lllllr}
\hline Subcriterion & C41 & C42 & C43 & Local (\%) & Overall (\%) \\
\hline Community investment (C41) & 1 & 1.2 & 1.2 & 38 & 10 \\
Gender equality (C42) & $1 / 1.2$ & 1 & 1 & 31 & 8 \\
Gender wage isonomy (C43) & $1 / 1.2$ & 1 & 1 & 31 & 8 \\
\hline
\end{tabular}

Table 11

Assessment of sustainability programs (AHP — differently weighted criteria)

\begin{tabular}{lll}
\hline Sustainability program & Overall score & Rank \\
\hline E1 & 0.30 & 4 \\
E2 & 0.69 & 1 \\
E3 & 0.48 & 3 \\
E4 & 0.23 & 6 \\
E5 & 0.58 & 2 \\
E6 & 0.24 & 5 \\
\hline
\end{tabular}

matrix's right eigenvalue. Overall weights were obtained weighting local weights by criterion's weight (Table 7).

Table 11 presents a new decision vector, with decision matrix (Table 5), weighted by overall weights of subcriteria (Tables 7-10).

Despite differences, the results from Tables 6 and 11 are very close. They have the same rank. One difference is that E1's and E3's sustainability programs were only $2 \%$ apart in Table 6, but $18 \%$ apart in Table 11. This difference is due to a $12 \%$ increase in C1's weight, from $10 \%$ to $22 \%$.

Figure 4 presents the sensitivity of alternatives' overall scores to C1's weight. Three dashed vertical lines in red are plotted for C1's weights of $10 \%, 22 \%$, and $30 \%$.

As can be seen in Fig. 4, E2 and E5 have the highest overall scores, independently of C1's weight. E3 is the most favored sustainability program with an increase in C1's weight. These three sustainability programs have an auditing process. On the other hand, E1 is the most unfavored sustainability program with an increase in C1's weight. With equally weighted criteria, in 10\%, E1's and E3's overall scores are closely tied at $0.36-0.38$. Increasing C1's weight to 30\%, E1's overall score decreases to 0.28 and E3's overall score increases to 0.52 .

The right edge of the sensitivity graph coincides with the binary column $\mathrm{C} 1$ from Table 5 . With C1's weight equal to $100 \%$, all other criteria have no weight. This is an extreme situation in which TBL measures from the GRI database are not considered. It is similar to if a company is auditing 


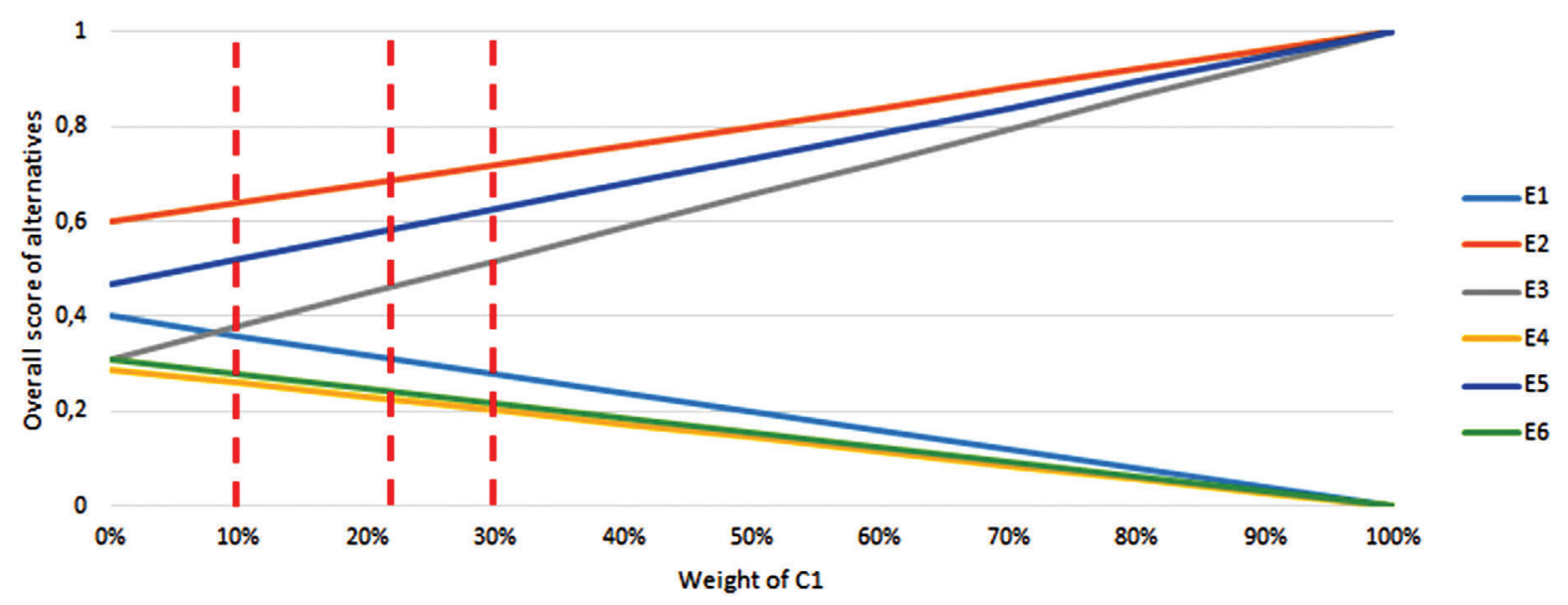

Fig. 4. Sensitivity of overall scores to C1's weight (AHP).

Table 12

Normalized scores for TOPSIS application

\begin{tabular}{lllllllllll}
\hline Sustainability program & C1 & C21 & C22 & C23 & C31 & C32 & C33 & C41 & C42 & C43 \\
\hline E1 & 0.00 & 0.04 & 0.04 & 0.02 & 0.04 & 0.06 & 0.02 & 0.06 & 0.06 & 0.02 \\
E2 & 0.10 & 0.04 & 0.06 & 0.06 & 0.06 & 0.04 & 0.06 & 0.08 & 0.06 & 0.08 \\
E3 & 0.10 & 0.04 & 0.02 & 0.02 & 0.04 & 0.02 & 0.04 & 0.02 & 0.06 & 0.02 \\
E4 & 0.00 & 0.04 & 0.02 & 0.02 & 0.02 & 0.04 & 0.02 & 0.06 & 0.02 & 0.02 \\
E5 & 0.10 & 0.08 & 0.06 & 0.06 & 0.02 & 0.02 & 0.04 & 0.04 & 0.06 & 0.04 \\
E6 & 0.00 & 0.04 & 0.02 & 0.02 & 0.02 & 0.04 & 0.02 & 0.06 & 0.04 & 0.02 \\
NIS & 0.00 & 0.04 & 0.02 & 0.02 & 0.02 & 0.02 & 0.02 & 0.02 & 0.02 & 0.02 \\
PIS & 0.10 & 0.08 & 0.06 & 0.06 & 0.06 & 0.06 & 0.06 & 0.08 & 0.06 & 0.08 \\
\hline
\end{tabular}

its sustainability itself, it is enough. Of course this is not enough, and this is visible on the other edge of the sensitivity graph. On the left edge, overall scores of sustainability programs are obtained with no weight for $\mathrm{C} 1$, or else, $0 \%$. The overall score for $\mathrm{E} 1$ is greater than E3's score. As the saying goes, "It is not enough to do things right. It is also necessary to do the right things" (Drucker and Maciariello, 2005). On the other hand, as E3 is an audited sustainability program and E1 is not, it seems that E3 is doing things right, and E1 is doing the right things. Both of them may be improved, to score as E2.

\subsection{TOPSIS application}

Table 12 presents the normalization of scores from Table 5, equally weighting attributes, for the TOPSIS application. This table also presents the NIS and the PIS. As can be seen, there are opportunities to improve E1 in C1, C21, C23, C33, and C43. For these criteria, E1 is closer to NIS than PIS. E2 can be improved for C21, the only criterion E2 is closer to NIS than PIS. Then, E3 can be improved for C21, C22, C23, C32, C41, and C43. E4 and E6 can be improved for all criteria except 
Table 13

Assessment of sustainability programs (TOPSIS)

\begin{tabular}{lllll}
\hline Sustainability program & $d_{i}^{-}$ & $d_{i}^{+}$ & Overall score & Rank \\
\hline E1 & 0.13 & 0.43 & 0.24 & 4 \\
E2 & 0.52 & 0.04 & 0.92 & 1 \\
E3 & 0.29 & 0.28 & 0.51 & 3 \\
E4 & 0.06 & 0.51 & 0.10 & 6 \\
E5 & 0.41 & 0.16 & 0.73 & 2 \\
E6 & 0.07 & 0.50 & 0.13 & 5 \\
\hline
\end{tabular}

for C41, the only criterion they are closer to PIS than NIS. And E5 can be improved for C31, C32, C33, C41, and C43.

Table 13 presents the decision vector with TOPSIS. Figure 5 presents a spiderweb chart of sustainability programs' scores. For better visualization, the scores are not normalized, as in Table 12. Therefore, PIS $=1$ and NIS $=0$, for every criterion.

The main analysis from Fig. 5 is the dominance of sustainability programs E2 and E5, respectively, colored in orange and blue. These alternatives have the greatest areas in the spiderweb graph, so they have higher scores according to criteria, individually.

Tables 6 and 13 present equal ranks. E2's and E5's sustainability programs have the two highest overall scores with both AHP and TOPSIS. E4's and E6's sustainability programs have the two lowest scores according to both methods. TOPSIS scores are more dispersed varying from 0.10 to 0.92 against a range from 0.23 to 0.69 with AHP.

Figure 6 presents sensitivity of overall scores to C1's weight. The sensitivity analysis of TOPSIS is similar to AHP: E2 and E5 will have the highest overall score, independently of C1's weight. E3 is also most favored by an increase in C1's weight. The great difference between AHP's and TOPSIS's sensitivity graph is in the curves. In AHP's sensitivity graph, the sensitivity of overall scores of C1's weight is linear. In TOPSIS's sensitivity graph the sensitivity is not linear. This nonlinearity makes the distances among the alternatives greater in TOPSIS than in AHP. For instance, on the left edge, the overall score for E3 is less than 0.2, much lower than E1's 0.4.

\subsection{Results and discussion}

Two applications of AHP were presented: one with equally weighted criteria and another with differently weighted criteria. For the second application, pairwise comparisons were provided by two coauthors of this paper, with previous experience of sustainability analysis of industries and also with expertise in MCDA. For TOPSIS, only one application, with equally weighted criteria, was presented. Therefore, the sensitivity of alternative overall scores on criteria weights was analyzed.

The application of both AHP and TOPSIS methods resulted in the same ranks. Each application also provided overall scores for sustainability programs. Thereby, an assessment index was provided by both applications, but the value for every alternative diverges with the application (Tables 6,11 , and 13). 


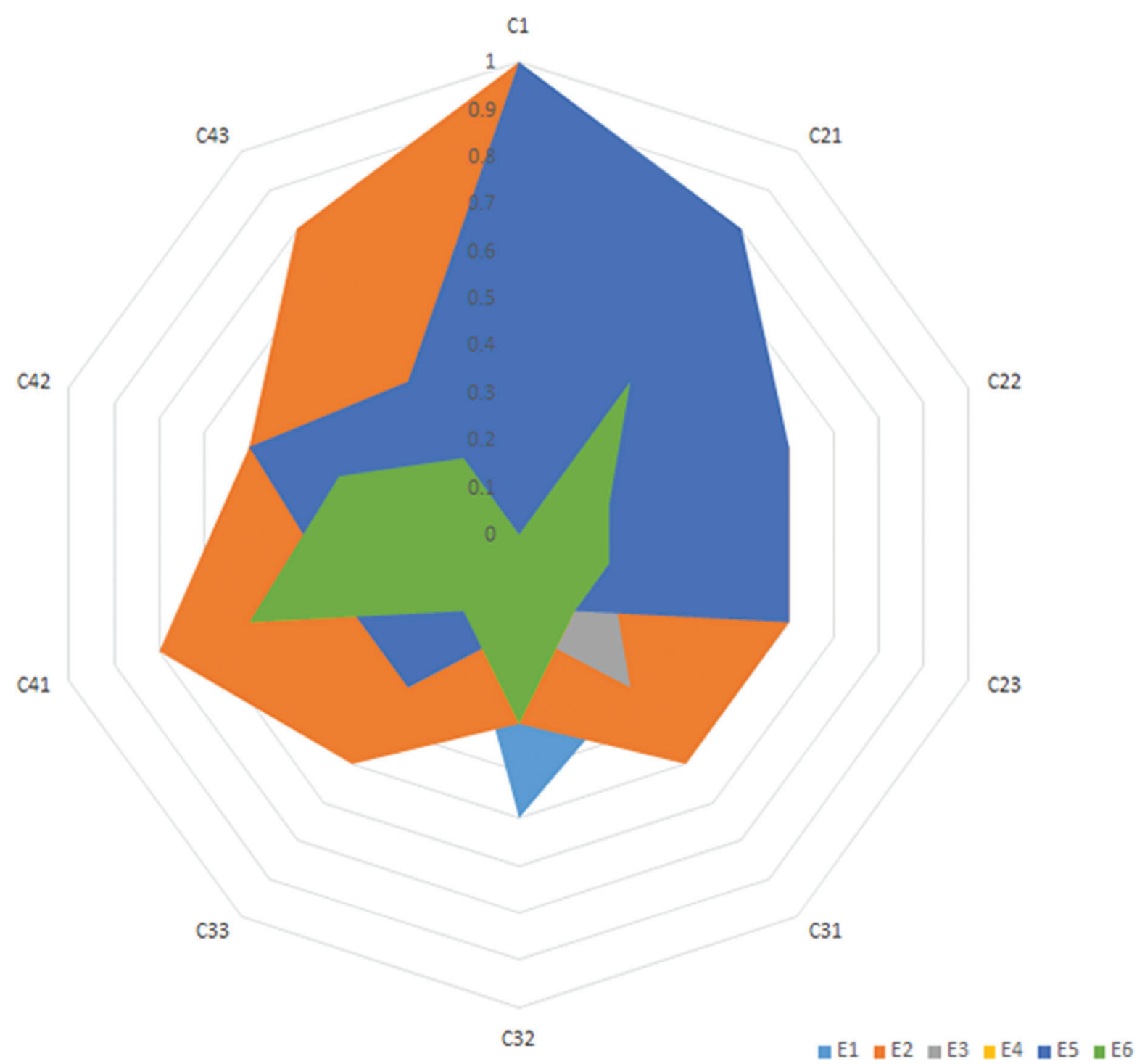

Fig. 5. Spiderweb chart of sustainability programs scores (TOPSIS).

Dispersion is an aspect of divergence among overall scores with different applications. For instance, the overall score for E5 is 0.52 with an AHP application, but it is 0.73 with TOPSIS. Then, with 0.51 one can consider E5 as an average sustainability program. Otherwise, with 0.73 one can consider E5 as a very good sustainability program. This particular example resulted from an audited sustainability program, rated as good $(\mathrm{G})$ to very good $(\mathrm{V})$ for economic subcriteria, weak (W) to reasonable (R) for environmental and $\mathrm{R}$ to $\mathrm{G}$ for social (Table 4). Thereby, according to its performance, E5 is an average sustainability program, as resulting from AHP applications. However, considering other sustainability programs, E5 is an above-average sustainability program, as 


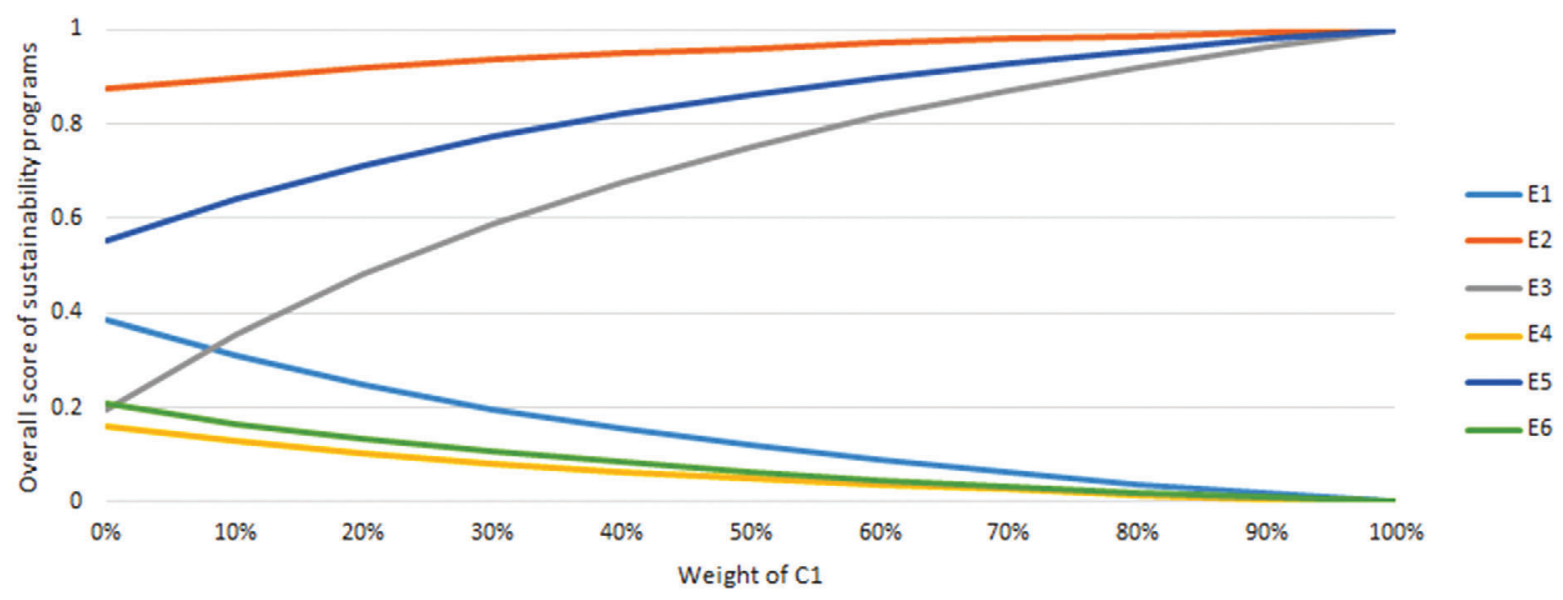

Fig. 6. Sensitivity of overall scores to C1's weight (TOPSIS).

shown by TOPSIS. This may be the subject of contextual analysis. In a world in need of care for the environment, the first assessment would be fair. In a world under economic crisis, the second assessment becomes more pertinent. And we know how this context changes. When this work was first submitted, before the outbreak of COVID-19, the TOPSIS results seemed more pertinent due to the world's economic and political crises. Now, ending the revision in COVID-19, the AHP results have become more real. Therefore, the final message in this section is the need to pay attention as everything can change. Nothing should be taken as eternal.

\section{Conclusions}

This paper presents applications of two different methods for MCDA-AHP, and TOPSIS - in the assessment of sustainability programs of six companies. A TBL-based model with 10 attributes is proposed. Data were collected from GRI, the most worldwide recognized sustainability database. Sensitivity analysis was conducted, endorsing the results.

AHP and TOPSIS applications resulted in the same ranks for E1-E6. Overall scores for sustainability programs diverged. With AHP, overall scores were centered, varying from 0.23 to 0.69 . With TOPSIS, they were more dispersed, varying from 0.10 to 0.92 . As mentioned in Section 4.4, the little difference in E5 overall score from 0.52 (with AHP) to 0.73 (with TOPSIS) may lead to different assessment from average to above average.

To solve the problem of sustainability program assessment, both method applications are not required. Thereby, just AHP, or just TOPSIS, may be applied. Despite being contextual, this analysis is a major contribution of this paper. Centered overall scores are expected when alternatives are really competitive or homogeneous. For those cases, this paper indicates use of the AHP application. Otherwise, disperse scores may be more useful, when programs in different stages are assessed. For instance, when monthly aged programs are compared with yearly aged programs. Then, alternatives may be more heterogeneous. In this case, this paper indicates use of the TOPSIS application. 
The proposed model was tested in an important industry of its global supply chain: Brazilian top companies of the Brazilian textile industry. The model can be generalized for other companies, industries, or locations, mutatis mutandis. Therefore, this is the first suggestion for future studies: application of the MCDA model in aerospace, automotive, electronics, or other industrial branches. The model may also be tested in multinational or transnational companies, outside Latin America, to prove its applicability.

The methods for MCDA were applied just with spreadsheets. This is not only due to the simplicity of the model, but mainly due to the experience of the coauthors on methods for MCDA. Application of hybrid or more complex methods for MCDA, such as fuzzy TOPSIS or T2FAHP, are other sources for further research.

\section{Acknowledgments}

Authors express their gratitude to Sao Paulo Research Foundation (FAPESP grant no. 2017/22963-6).

\section{References}

ABIT, 2019. Brazilian Association of Textile and Apparel Industry. Available at https://www.abit.org.br/cont/perfildo-setor (accessed May 29, 2020).

Acar, E., Kiliç, M., Güner, M., 2015. Measurement of sustainability performance in textile industry by using a multicriteria decision making method. Textile and Apparel 25, 3-9.

Appel, M., 2019. Life cycle assessment of production of cotton knits [in Brazilian Portuguese]. Senior Project on Environmental Engineering, Universidade Federal de Santa Catarina, Santa Catarina.

Bal, H., Orkcu, H.H., Celebioglu, S., 2010. Improving the discrimination power and weights dispersion in the data envelopment analysis. Computers \& Operations Research 37, 99-107.

Bana e Costa, C.A., Vansnick, J., 1994. MACBETH — an interactive path towards the construction of cardinal value functions. International Transactions in Operational Research 1, 4, 489-500.

Bansal, P., Des Jardine, M.R., 2014. Business sustainability: it is about time. Strategic Organization 12, 1, 70-78.

Barzilai, J., 1998. On the decomposition of value functions. Operations Research Letters 22, 4-5, 159-170.

Belton, V., Gear, T., 1983. On a shortcoming of Saaty's method of analytic hierarchies. Omega 11, 3, $228-230$.

Bertrand, J.W.M., Fransoo, J.C., 2002. Operations management research methodologies using quantitative modeling. International Journal of Operations \& Production Management 22, 2, 241-264.

Borowy, I., 2014. Defining Sustainable Development for Our Common Future: a history of the World Commission on Environment and Development (Brundtland Commission). Routledge, New York, NY.

Brans, J.P., Vincke, P., 1985. NOTE - a preference ranking organisation method. Management Science 31, 6, 647-656.

Cagniuc, P.A., 2017. Markov Chains: From Theory to Implementation and Experimentation. Wiley, Hoboken, NJ.

Charnes, A., Cooper, W.W., Rhodes, E., 1978. Measuring the efficiency of decision making units. European Journal of Operational Research 2, 6, 429-444.

Creswell, J.W., 2013. Research Design: Qualitative, Quantitative, and Mixed Methods Approaches. Sage, Thousand Oaks, CA.

Cruz-Moreira, J.R., 2002. New strategies and internet use in Brazilian apparel productive chains. Proceedings of the POMS Annual Conference. Production and Operations Management Society, San Francisco, CA, p. 94.

De Felice, F., Petrillo, A., 2013. Absolute measurement with analytic hierarchy process: a case study for Italian racecourse. International Journal of Applied Decision Sciences 6, 3, 209-227. 
Do Amaral, M.C., Zonatti, W.F., Da Silva, K.L., Karam Júnior, D., Amato Neto, J., Baruque-Ramos, J., 2018. Industrial textile recycling and reuse in Brazil: case study and considerations concerning the circular economy. Gestão \& Produção 25, 3, 431-443.

Dong, Q., Saaty, T.L., 2014. An analytic hierarchy process model of group consensus. Journal of Systems Science and Systems Engineering 23, 3, 362-374.

Drucker, P.F., Maciariello, J.A., 2005. The Effective Executive in Action: A Journal for Getting the Right Things Done. HarperCollins, New York, NY.

Dyer, J.S., 1990. Remarks on the analytic hierarchy process. Management Science 36, 3, 247-258.

Eccles, R.G., Ioannou, I., Serafeim, G., 2014. The impact of corporate sustainability on organizational processes and performance. Management Science 60, 11, 2835-2857.

Elkington, J., 1999. Cannibals with Forks: The Triple Bottom Line of 21st Century Business. Capstone, North Mankato, MN.

Fontaine, M., 2013. Corporate social responsibility and sustainability: the new bottom line? International Journal of Business and Social Science 4, 4, 110-119.

Geissdoerfer, M., Morioka, S.N., De Carvalho, M.M., Evans, S., 2018. Business models and supply chains for the circular economy. Journal of Cleaner Production 190, 712-721.

GRI, 2019. Global reporting initiative. Technical Report. Available at https://www.globalreporting.org (accessed May 29, 2020).

Harker, P.T., 1987. Incomplete pairwise comparisons in the analytic hierarchy process. Mathematical Modelling 9, 11, 837-848.

Hutchins, M.J., Richter, J.S., Henry, M.L., Sutherland, J.W., 2019. Development of indicators for the social dimension of sustainability in a U.S. business context. Journal of Cleaner Production 212, 687-697.

Hwang, C.L., Yoon, K., 1981. Multiple Attribute Decision Making Methods and Applications: A State-of-the-Art Survey. Springer, New York, NY.

Ilangkumaran, M., Kumanan, S., 2009. Selection of maintenance policy for textile industry using hybrid multi-criteria decision making approach. Journal of Manufacturing Technology Management 20, 7, 1009-1022.

International Monetary Fund, 2020. World Economic Outlook. Available at https://www.imf.org/en/publications/weo (accessed May 29, 2020).

Ishizaka, A., Lusti, M., 2004. An expert module to improve the consistency of AHP matrices. International Transactions in Operational Research 11, 1, 97-105.

Ishizaka, A., Nemery, P., 2013. Multi-criteria Decision Analysis: Methods and Software. Wiley, Chichester.

Jensen, M., 2001. Value maximisation, stakeholder theory, and the corporate objective function. European Financial Management 7, 3, 297-317.

Joshi, R., Banwet, D.K., Shankar, R., 2011. A Delphi-AHP-TOPSIS based benchmarking framework for performance improvement of a cold chain. Expert Systems with Applications 38, 8, 10170-10182.

Kaebernick, H., Kara, S., Sun, M., 2003. Sustainable product development and manufacturing by considering environmental requirements. Robotics and Computer-Integrated Manufacturing 19, 6, 461-468.

Kaplan, R.S., Norton, D.P., 1992. The balanced scorecard-measures that drive performance. Harvard Business Review 70, 1, 71-79.

Keeney, R.L., Raiffa, H., 1976. Decisions with Multiple Objectives: Preferences and Value Trade-Offs. Wiley, New York, NY.

Kennerley, M., Neely, A., 2002. Performance measurement frameworks: a review. In Neely, A. (ed.) Business Performance Measurement: Theory and Practice. Cambridge University Press, Cambridge, pp. 145-155.

Khan, S.A., Chaabane, A., Dweiri, F.T., 2015. Multi-criteria decision-making methods application in supply chain management: a systematic literature review. In Salomon, V. (ed.) Multi-Criteria Methods and Techniques Applied to Supply Chain Management. InTech Open, London, pp. 3-31.

Koksalan, M., Wallenius, J., Zionts, S., 2011. Multiple Criteria Decision Making: From Early History to the 21st Century. World Scientific, Singapore.

Kono, N., 2014. Brundtland Commission (World Commission on Environment and Development). In Michalos, A.C. (ed.) Encyclopedia of Quality of Life and Well-Being Research. Springer, Dordrecht, pp. 450-452.

Lai, Y.J., Liu, T.Y., Hwang, C.L., 1994. TOPSIS for MODM. European Journal of Operational Research 76, 3, 486500.

(C) 2020 The Authors.

International Transactions in Operational Research (C) 2020 International Federation of Operational Research Societies 
Li, X.B., Reeves, G.R., 1999. A multiple criteria approach to data envelopment analysis. European Journal of Operational Research 115, 507-517.

Lin, M.C., Wang, C.C., Chen, M., Chang, C.A., 2008. Using AHP and TOPSIS approaches in customer-driven product design process. Computers in Industry 59, 1, 17-31.

Linkov, I., Moberg, E., 2012. Multi-Criteria Decision Analysis: Environmental Applications and Case Studies. CRC Press, Boca Raton, FL.

Lootsma, F.A., 1993. Scale sensitivity in the multiplicative AHP and SMART. Journal of Multi-Criteria Decision Analysis 2, 2, 87-110.

Marimon, F., Alonso-Almeida, M.D.M., Rodríguez, M.D.P., Alejandro, K.A.C., 2012. The worldwide diffusion of the Global Reporting Initiative: What is the point? Journal of Cleaner Production 33, 132-144.

McCord, M., De Neufville, R., 1983. Empirical demonstration that expected utility decision analysis is not operational. In Stigum, B.P., Wenstøp, F. (eds) Foundations of Utility and Risk Theory with Applications. Springer, Dordrecht, pp. 181-199.

Medel-González., F., García-Ávila, L.F., Salomon, V.A.P., Marx-Goméz, J., Hernandéz, C.T., 2016. Sustainability performance measurement with analytic network process and balanced scorecard: Cuban practical case. Production 26, 3, 527-539.

Medel-González, F., Salomon, V.A.P., García-Ávila, L., 2015. Multi-criteria sustainability performance measurement: an application in Cuba. International Journal of Business and Systems Research 9, 4, 394-411.

Metaxas, I.N., Koulouriotis, D.E., Spartalis, S.H., 2013. Business excellence index of a firm with fuzzy AHP and TOPSIS. Benchmarking: An International Journal 23, 6, 1522-1557.

Millet, I., Saaty, T.L., 2000. On the relativity of relative measures-accommodating both rank preservation and rank reversals in the AHP. European Journal of Operational Research 121, 1, 205-212.

Montabon, F., Pagell, M., Wu, Z., 2016. Making sustainability sustainable. Journal of Supply Chain Management 52, 2 , 11-27.

Nadaban, S., Dzitac, S., Dzitac, I., 2016. Fuzzy TOPSIS: a general view. Procedia Computer Science 91, 823-831.

Nazam, M., Xu, J., Tao, Z., Ahmad, J., Hashim, M., 2015. A fuzzy AHP-TOPSIS framework for the risk assessment of green supply chain implementation in the textile industry. International Journal of Supply and Operations Management 2, 1, 548-568.

Oliveira, M., Fontes, D.B.M.M., Pereira, T., 2018. Evaluating vehicle painting plans in an automobile assembly plant using an integrated AHP-PROMETHEE approach. International Transactions in Operational Research 25, 4, 13831406.

Oliveira, V.A.R., Salomon, V.A.P., Soares, L.S., Monticelli, F.M., Atílio, I., 2016. Análise multicritério com DEA e AHP da seleção de equipamentos de ar-condicionado. Anais do Encontro Nacional de Engenharia de Produção. Brazilian Association of Industrial Engineering, João Pessoa, pp. 1-9.

Ortiz-Barrios, M.A., Herrera-Fontalvo, Z., Rúa-Muñoz, J., Ojeda-Gutiérrez, S., De Felice, F., Petrillo, A., 2018. An integrated approach to evaluate the risk of adverse events in hospital sector: from theory to practice. Management Decision 56, 10, 2187-2224.

Ortiz-Barrios, M., Miranda-De La Hoz, C., López-Meza, P., Petrillo, A., De Felice, F., 2020. A case of food supply chain management with AHP, DEMATEL, and TOPSIS. Journal of Multi-Criteria Decision Analysis 27, 1-2, $104-128$.

Rodrigues, L.V.S., Casado, R.S.G.R., De Carvalho, E.N., Silva, M.M., E Silva, L.C., 2020. Using FITRADEOFF in a ranking problem for supplier selection under TBL performance evaluation: an application in the textile sector. Production 30. 10.1590/0103-6513.20190032.

Roy, B., 1968. Classement et choix en présence de points de vue multiples (la méthode ELECTRE). Revue française d'informatique et de recherche opérationnelle 2, 8, 57-75.

Rycroft, T., Wood, M., Zemba, V., Kennedy, A., Weiss, C., Desmet, D., Ali, R., Linkov, I., 2019. Assessing the sustainability of advanced materials using multi criteria decision analysis and the triple bottom line. Integrated Environmental Assessment and Management 15, 6, 1021-1028.

Saaty, T.L., 1974. Measuring the fuzziness of sets. Journal of Cybernetics 4, 4, 53-61.

Saaty, T.L., 1977. A scaling method for priorities in hierarchical structures. Journal of Mathematical Psychology 15, 3, $234-281$.

Saaty, T.L., 1986. Absolute and relative measurement with the AHP. The most livable cities in the United States. SocioEconomic Planning Sciences 20, 6, 327-331. 
Saaty, T.L., 1996. Decision Making with Dependence and Feedback: The Analytic Network Process (1st edn). RWS, Pittsburgh, PA.

Saaty, T.L., 2005. Theory and Applications of the Analytic Network Process: Decision Making with Benefits, Opportunities, Costs, and Risks. RWS, Pittsburgh, PA.

Saaty, T.L., 2010. Principia Mathematica Decernendi: Mathematical Principles of Decision Making. RWS, Pittsburgh, PA.

Saaty, T.L., Ozdemir, M., 2003. Why the magic number seven plus or minus two. Mathematical and Computer Modelling $38,3-4,233-244$.

Saaty, T.L., Rogers, P.C., 1976. Higher education in the United States (1985-2000): Scenario construction using a hierarchical framework with eigenvector weighting. Socio-Economic Planning Sciences 10, 6, 251-263.

Saaty, T.L., Vargas, L.G., Whitaker, R., 2009. Addressing with brevity criticisms of the analytic hierarchy process. International Journal of the Analytic Hierarchy Process 1, 2, 121-134.

Salgado, E.G., Salomon, V.A.P., Mello, C.H.P., 2012. Analytic hierarchy prioritisation of new product development activities for electronics manufacturing. International Journal of Production Research 50, 17, 4860-4866.

Salomon, V.A.P., 2016. Absolute measurement and ideal synthesis on AHP. International Journal of the Analytic Hierarchy Process 8, 3, 538-545.

Salomon, V.A.P., Tramarico, C.L., Marins, F.A.S., 2016. Analytic hierarchy process applied to supply chain management. In De Felice, F., Saaty, T.L., Petrillo, A. (eds) Applications and Theory of Analytic Hierarchy Process: Decision Making for Strategic Decisions. InTech Open, London, pp. 1-16.

Sato, Y., 2004. Comparison between multiple-choice and analytic hierarchy process: measuring human perception. International Transactions in Operational Research 11, 1, 77-86.

Shiu, J.Y., Lu, S.T., Chang, D.S., Wu, K.W., 2019. Fuzzy multicriteria decision-making tools for selecting a professional property management company. International Transactions in Operational Research 26, 4, 1527-1557.

Shyjith, K., Ilangkumaran, M., Kumanan, S., 2008. Multi-criteria decision-making approach to evaluate optimum maintenance strategy in textile industry. Journal of Quality in Maintenance Engineering 14, 4, 375-386.

Siew, R.Y., 2015. A review of corporate sustainability reporting tools (SRTs). Journal of Environmental Management 164, 180-195.

Stoycheva, S., Marchese, D., Paul, C., Padoan, S., Juhmani, A.S., Linkov, I., 2018. Multi-criteria decision analysis framework for sustainable manufacturing in automotive industry. Journal of Cleaner Production 187, $257-272$.

Subramanian, V., Semenzin, E., Hristozov, D., Marcomini, A., Linkov, I., 2014. Sustainable nanotechnology: defining, measuring and teaching. Nano Today 9, 1, 6-9.

Svensson, G., Ferro, C., Høgevold, N., Padin, C., Varela, J.C.S., Sarstedt, M., 2018. Framing the triple bottom line approach: direct and mediation effects between economic, social and environmental elements. Journal of Cleaner Production 197, 1, 972-991.

Svensson, G., Wagner, B., 2015. Implementing and managing economic, social and environmental efforts of business sustainability: propositions for measurement and structural models. Management of Environmental Quality 26, 2 , 195-213.

Tramarico, C.L., Mizuno, D., Salomon, V.A.P., Marins, F.A.S., 2015. Analytic hierarchy process and supply chain management: a bibliometric study. Procedia Computer Science 55, 441-450.

Triantaphyllou, E., 2000. Multi-Criteria Decision Making Methods: A Comparative Study. Springer, Dordrecht.

Tyagi, M., Kumar, P., Kumar, D., 2014. A hybrid approach using AHP-TOPSIS for analyzing e-SCM performance. Procedia Engineering 97, 2195-2203.

Wallenius, J., Dyer, J.S., Fishburn, P.C., Steuer, R.E., Zionts, S., Deb, K., 2008. Multiple criteria decision making, multiattribute utility theory: recent accomplishments and what lies ahead. Management Science 54, 7, 1336-1349.

Watróbski, J., Jankowski, J., Ziemba, P., Karczmarczyk, A., Zioło, M., 2019. Generalised framework for multi-criteria method selection. Omega 86, 107-124.

WCED, 1987. Our common future. Available at https://sustainabledevelopment.un.org/content/documents/5987ourcommon-future.pdf (accessed May 29, 2020).

Whitaker, R., 2007a. Criticisms of the analytic hierarchy process: why they often make no sense. Mathematical and Computer Modelling 46, 7-8, 948-961.

Whitaker, R., 2007b. Validation examples of the analytic hierarchy process and analytic network process. Mathematical and Computer Modelling 46, 7-8, 840-859. 
Wu, J., Pap, E., Szakal, A., 2018. Two kinds of explicit preference information oriented capacity identification methods in the context of multicriteria decision analysis. International Transactions in Operational Research 25, 3, 807-830.

Yatsalo, B.I., Kiker, G.A., Kim, J., Bridges, T.S., Seager, T.P., Gardner, K., Satterstrom, F.K., Linkov, I., 2007. Application of multicriteria decision analysis tools to two contaminated sediment case studies. Integrated Environmental Assessment and Management 3, 2, 223-233.

Yeh, C.H., 2002. A problem-based selection of multi-attribute decision-making methods. International Transactions in Operational Research 9, 2, 807-830.

Yin, R.K., 2017. Case Study Research and Applications: Design and Methods. Sage, Thousand Oaks, CA.

Zavadskas, E.K., Turskis, Z., Kildiene, S., 2014. State of art surveys of overviews on MCDM/MADM methods. Technological and Economic Development of Economy 20, 1, 165-179.

Zionts, S., 1979. MCDM - if not a Roman numeral, then what? INFORMS Journal on Applied Analytics 9, 4, 94-101. 